\title{
Las poéticas del Renacimiento
}

La transformación operada por el Renacimiento florentino en los primeros decenios del Quattrocento se inicia con el arte, acompanado éste por una conciencia teorica de la que son testimonios los tratados de Ghiberti y de L. B. Alberti, a los que siguieron los escritos de Leonardo, y las paralelas reflexiones sobre la poesía. El arte fue el focus de irradiación del Renacimiento. El nuevo espíritu renacentista se manifiesta en las artes figurativas, en la poesía, en la política, en la vida historica, sin encontrar eco inmediato en el pensamiento filos 6 fico. De hecho el humanismo de la primera mitad del Quattrocento fue un gran movimiento cultural que por su esencia no fue filosófico, y que, sin embargo, tuvo consecuencias filosбficas muy importantes. $Y$ se puede añadir que es precisamente la arquitectura la que está a la vanguardia de las grandes transformaciones del siglo. La vigorosa labor arquitectónica va al mismo paso que la teorización del arte; Brunelleschi, empeñado en levantar la cúpula de Santa María del Fiore, y Alberti, quien lo acompaña siempre con sus reflexiones, llegan a la nueva representación espacial: la tridimensionalidad del espacio, resultado de una nueva visión del mundo que pronto repercutió en los grandes descubrimientos de finales del siglo.

Hay que detenerse un instante sobre el término Renacimiento, cuyo significado, extensión temporal y espacial, y complejidad han sido y siguen siendo objeto de innumerables estudios; y, sobre todo, detener la atención sobre el gran tópico del "retomo a 
la antigüedad clásica", que es el punto de partida de las reflexiones estéticas del Quattro-Cinquecento que, como dice Kristeller, ha dominado con su cultura el horizonte occidental por varios siglos.

La afirmación y la exaltación del individuo, de su libertad, más bien de su libre albedrío, la defensa y celebración de la vida del hombre sobre la tierra, de sus pasiones atemperadas por la virtud, de esa realidad humana caduca para la escolástica, junto con la idea de una nueva relación con lo divino que había empezado a delinearse en Francisco de Asís, se acompañan con el mito del 'retomo' a la antigüedad clásica. Y hay que subrayar de una vez que el retorno a los clásicos no es la causa de la mudada visión del humanismo, sino el efecto de ella. No es el mundo clásico el que determina la nueva visión de los cuatrocentistas, sino su nueva apertura al mundo la que dirige su atención hacia los clásicos grecorromanos, con los que descubren afinidades de intereses, una dimensión del hombre como "medida de todas las cosas"; una contigüidad espiritual que los distancia del medioevo y los acerca a los antiguos, a los que eligen como maestros de vida, como modelos ejemplares de humanidad a seguir, para encontrarse a sí mismos e 'ir más lejos'. Por eso los clásicos se vuelven punto de referencia y de confrontación constante, para llegar a la altura de ellos sin perder la propia originalidad. No hubo imitación servil de los antiguos y, si la hubo, fue la de los mediocres que no faltan en ninguna época de la historia.

También el medioevo se había acercado al mundo antiguo, a los poetas clásicos, pero es otro el espíritu con que se acerca y, de la confrontación de su postura y la de los humanistas frente a ellos, se pueden entender las divergencias que los separan, así como las convergencias que también existen. Los intelectuales de la Edad Media se habían acercado al mundo clásico con admiración, pero sin la preocupación de los humanistas por penetrar en la esencia de su obra, fuera de todo presupuesto religioso o doctrinal, y sin traicionar su espíritu; en fin, sin la preocupación de descubrirla en su autenticidad, al contrario de los padres y los 
doctores de la iglesia quienes habían buscado conciliarla con el espíritu cristiano, reduciéndola a una finalidad ausente en el mundo clásico. Su interpretación fue instrumentalizada a fin de construir el edificio especulativo cristiano, la gran, abstracta y rica "catedral de ideas" contra la cual se rebelaron los humanistas. Por otro lado, los intelectuales del medioevo no conocían el griego y sólo tenían un acceso indirecto a las obras griegas, mediado a través del vehículo de las traducciones al latín, mientras que los humanistas lo aprenden y lo introducen en los programas de estudio de las escuelas y de las universidades. Y. más, la invención de la imprenta y del papel, al facilitar la edición de obras en serie y al disminuir los costos del libro, permiten su más amplia difusión y multiplican el número de las bibliotecas que en la Edad Media estaban limitadas a los conventos.

Diversa es, pues, la actitud de los humanistas que someten todos los códigos de la antigüedad, así como los nuevos que ellos mismos descubren (Lucrecio, Tácito, Manilio, etc., obras de Cicerón desconocidas en la Edad Media, como las Cartas, el Brutus, las Oraciones, etc.) a un cotejo riguroso, para reconstruir un original que no sólo la ideología cristiana, sino los mismos amanuenses habían a veces alterado por ignorancia o por cansancio, ${ }^{1}$ para luego proceder a un severo análisis lingüístico que permitiera una rigurosa reinterpretación de la palabra y del texto, en cuanto pensamiento. Es el inicio de la filología. El método filologico que Valla indiferentemente aplica a temas religiosos y mundanos, se extiende a Erasmo y a Lutero, quienes lo aplicarán en la revisión del Nuevo Testamento y de los textos religiosos. Al lado de la filología surge también la arqueología, que empieza con los descubrimientos etruscos y, contemporáneamente, con los estudios de los monumentos y de las ruinas romanas, hechas in loco por Alberti.

Ya en el siglo anterior el poeta Francesco Petrarca, que no por nada es considerado un humanista ante literam, había enfrentado

${ }^{1}$ Hay que recordar que su labor se prolongaba hasta la noche, a la luz de velas. 
viajes fatigosos para buscar en las bibliotecas de los numerosos conventos europeos los diferentes códigos de un mismo libro, como por ejemplo, los textos de Tito Livio, al que luego estudia en sus Discursos Machiavello, para poder reconstruir su original, sirviéndose de la colaboración de un amanuense que tenía a su servicio en su misma casa. En el siglo posterior, el representante más maduro de la filología humanista, Lorenzo Valla, a quien Erasmo de Rotterdam consideraba su maestro, demuestra (De falsa donatione Constantini) la falsedad de la donación de Constantino a la Iglesia, un apócrifo creado por el papado para legitimar su poder temporal.

Otro tema predominante de la reflexión humanista sobre el arte es la poesía, considerada ya no ancilla teologiae o ancilla fidei como lo había sido por la escolástica, sino altera philosophia, instrumento de conocimiento que revela verdades profundas, de formación y elevación del hombre, que guía a la verdad y a la vida interior. En una carta a Boccaccio, como en muchos de sus escritos, Petrarca había exaltado la función educativa y liberadora que el estudio literario ejercía, despertando el amor de la virtud y disminuyendo el temor a la muerte. Esta exaltación se acompaña con el amor a la poesía antigua. En el Quattrocento los grandes maestros humanistas de la juventud, Vergerio, Vittorino da Feltre, etc., continúan su senda y, convencidos de la virtud formativa de la poesía, la eligen como base primordial de sus programas de estudio. Los humanistas remiten constantemente al mito de Orfeo que, junto con la anédocta de Xeusis, se vuelve un topos del discurso renacentista para exaltar la poesía como símbolo de la civilización humana. Con su cítara, Orfeo había amansado las fieras, habia hecho mover las piedras y las selvas, detenido los ríos, humanizado a los hombres todavía bárbaros, reduciéndolos a la vida comunitaria.

Junto a la poesía, el estudio de la lengua, del eloquium, a través del cual el hombre logra dominar sus medios expresivos y manifestar su pensamiento. La palabra es el don divino, medio de comunicación y comunión entre los hombres. El culto de la bella 
forma no es por tanto culto de una perfección formal, vacía, sino forma bella capaz de expresar el mundo interior del hombre, unidad entre forma y contenido, entre palabra y pensamiento. La célebre polémica entre Pico della Mirandola y el humanista Hermolao, quien defendía la tesis de la perfecta adecuación entre belleza literaria y doctrina, en contraste con Pico que defendfa la tesis opuesta de la libertad filosofica respecto de las leyes de la retorica, se resuelve en la necesidad de una síntesis entre expresión y conocimiento, de una precisión expresiva.

En 1482, a la edad de 22 años, Pico, gran conocedor de la filosofía escolástica, escribe una larga carta a Ermolao Barbaro -el 'divino' Ermolao, como lo llama Erasmo- en la que sale en defensa de los escolásticos. Pico reprocha al amigo la crítica de los humanistas en contra de los filósofos 'bárbaros' de la escolástica, por su "ruda, inculta, sórdida forma". Si uno de ellos pudiera regresar al mundo, se pregunta en la carta Pico, ¿cómo hubiera podido defenderse? "Si nos falló la elocuencia, no nos faltó la ciencia. El no haber conjugado ésta con aquélla está tan exento de culpa, como quizá lo hubiera estado conjugarla. ¿Quien, de hecho, no reprobaría en una honesta joven los perendengues y los cosméticos? Tan grande es el contraste entre el retórico y el filosofo que más no podría serlo. ¿Qué otra cosa más es el oficio del retórico sino mentir, engañar, envolver, embrollar? ¿Qué más es, en suma, la elocuencia sino puro embuste, impostura, engaño?" Sus argumentos son los de los averroístas de la universidad de Padua que Pico había frecuentado, en contra de los cuales se habían levantado en el siglo anterior las críticas de Petrarca y en el siglo Xvi se levantarán, entre otras, las de Lorenzo Valla quien dice que "no existen libros buenos escritos mal". En fin, Pico ataca una idea de la retórica - que por cierto no es la que profesan los humanistas-vacía de contenido, puro omamento; es decir, una retórica sofista, mera habilidad para persuadir, convencer, prescindiendo de una convicción racional, de un saber real. Es la retórica de los sofistas que Platón había criticado ásperamente porque la consideraba "más cerca del arte culinario que de 
la medicina, más dirigida a satisfacer el gusto que a mejorar a la persona". Sin embargo, Platón no niega a la retórica un valor substancial como lo hará Pico. Para el filósofo griego la retórica es "el arte de guiar al alma por el camino de los razonamientos", lo cual acerca la retórica a la filosofía. Es un poco la posición de Aristóteles, quien la considera la "contraparte de la dialéctica: la retórica es el arte de la persuasión que debe estar ligada, por medio de la dialéctica, a la filosofía, construcción esencial de todos los principios cognoscitivos".

Es curioso observar cómo el filosofo Pico, quien defiende a la filosofía de la retorica, utiliza sin embargo procedimientos retóricos, y con un estilo admirable (no sobra decir que Pico había escrito poesía, por cierto mediocre.) Quizá su violento rechazo a la retórica es debido no sólo a su respeto por la escolástica sino también al hecho de que a finales del siglo xv, cuando Florencia está en plena crisis, los humanistas empiezan a perderse èn ejercicios literarios artificiales, en un hueco virtuosismo; de manera que la polémica en contra de la 'barbarie' escolástica, a la cual se une más tarde Erasmo de Rotterdam con su Antibarbari, pudo haberlo indignado. Cuando se habla de 'barbarie', los humanistas como Barbaro se refieren a las doctrinas no sólo "mal expresadas sino también mal argumentadas, con sofismas y sutilezas" y con "ignorancia lingüística y burda simpleza". El protestante Melanchtón retomar la disputa Pico-Barbaro, sosteniendo la defensa de Ermolao en nombre de las buenas letras y de los buenos estudios en contra de la barbarie dañina también a la religión. La polémica forma-contenido se prolongará por siglos y, para dar un solo ejemplo, culmina en el Ottocento con Gustave Flaubert quien escribe en una carta del 12 de diciembre de 1857, a Mlle. Leroyer de Chantepie que "cuanto más bella es una idea, más armoniosa es la frase. La precisión del pensamiento hace (más bien es) la precisión del lenguaje." 
El fundamento del arte y de cada disciplina está en los modelos de la antigüedad. Los antiguos clásicos son los paradigmas de los modernos, son los maestros ejemplares a los que hay que imitar: para ser poetas hay que leer y meditar a Homero, Virgilio, Catulo u Horacio, así como quien quiera ser filósofo tendrá que leer a Platón y Aristóteles, y quien quiera ser artista deber conocer a Fidias, Apeles y Xeusis. El ejemplo más seguido y admirado es Cicerón, quien se vuelve el modelo perfecto de estilo y de lengua, testimonio, como dice Cesare Vasoli, de una costumbre ática y de una admirable técnica lingüística y oratoria al servicio de la comunidad. Pero este modelo, como dice también Vasoli, terminar transformándose en un rígido y cerrado código de reglas que degenerará en una preceptiva pedante, objeto de la sátira feroz de Erasmo de Rotterdam en su Ciceronianus. Es importante decir que Cicerón, cuyas reflexiones estéticas han sido evaluadas en su justa luz por Edmondo Cione y E. Panofsky, no es responsable de los excesos de sus epígonos, así como no lo es Petrarca del petrarquismo cincuecentista cuyo lenguaje afectado será objeto del remedo de Shakespeare en su Romeo y Julieta.

En el siglo xv triunfan los studia humanitatis que se compendian en el trivium - gramática, retórica, dialéctica- que domina todas las actividades del espíritu, y cuya impartición, fuera del ambiente estrictamente académico universitario, es encomendado a un personal nuevo. Aparte del trivium, quedan las que Alberti llama "artes del diseño" que comprenden arquitectura, escultura, pintura, dibujo, matemáticas y geometría, resumidas frecuentemente bajo el término de pictura. Sin embargo, Ghiberti y Alberti insisten en la necesidad de que el artista disponga de una amplia formación intelectual que abarque todas las formas del saber (gramática, historia, filosofía, medicina, anatomía, astrología...), porque las artes figurativas son ciencias de varias disciplinas y hay que enriquecerlas con varias enseñanzas. En fin, la operación que Alberti realiza y que llega a rescatar de su condición de arte- 
sano al artista (hay que considerar que en el Renacimiento este término todavía no existe y Vasari en sus Vidas utiliza el de artefice del disegno) elevándolo al rango de intelectual, es la de indicar el paralelismo dado entre las artes figurativas y la elocuencia -paralelismo ya notado en el mundo clásico: dum viguit eloquentia, viguit pictura (donde prospera la elocuencia, prospera la pintura)- - que le permite transferir la noción de retórica a la actividad artística, sin dejar de indicar como fundamento de las artes del diseño a la matemática, que es una de las artes liberales. Recurriendo a la retórica y a la poética de Aristoteles, al De inventione de Cicerón y a Quintiliano, Alberti transfiere a la pintura las nociones de la retorica concemientes a la literatura. Alberti distingue en la creación artística el ars (tecné) es decir, el estudio, respecto de la natura (phisis), es decir el ingenio. Lo primero, la tecné, es el rudimento, que correspondería a la inventio y la elocutio del discurso (en la pintura serían las reglas de proyección geométrica, el estudio objetivo de la naturaleza, etc.) y lo segundo, el ingenio del pintor. Se trata de una conversión, con palabras de Chastel, ${ }^{2}$ de las fórmulas de la poética y de la retórica antiguas, que dan bases sólidas a la célebre analogía, de origen clásico, ut poesis pictura, que subraya la hermandad de las artes: la pintura es poesía muda y la poesía pintura hablada (Plutarco). Citada frecuentemente por artistas y teóricos del Renacimiento (Leonardo, Lomazzo...), la formula es el principio de aquella unidad del arte que será proclamada firmemente en los siglos posteriores. Esta equiparación de las "artes del diseño" a la creación literaria, lleva evidentemente a exaltar la personalidad del artista y a dignificar y elevar la actividad artística — considerada hasta entonces producción mecánica y manual- al nivel de las artes liberales.

Problema central en el pensamiento teórico sobre el arte, es el de la imitación. La adhesión a la verdad natural se había impuesto en el siglo anterior con Giotto, celebrado con excepcional intuición por Boccaccio (Jomada IV Decamerón) y por el teórico

2 André Chastel, Art et humanisme. Florence au temps de Laurent le Magnifique, Presses Universitaires de France, París 1961. 
Cennino Cennini. Como se ha visto, la exigencia de la formación intelectual del artista es un requisito indispensable, y lo es también para que este pueda transformar la imitación en invención, ya que la imitación no tiene que ser copia pasiva, sino idealización de la realidad. Alberti observa que en el mundo empírico no existe belleza perfecta -observación ya hecha por Sócratesque ésta se encuentra dispersa en varios objetos, por tanto el artista, émulo de la naturaleza, debe corregirla y superarla. Recurriendo al ejemplo de Xeusis, insiste en la pluralidad de los modelos en los que el artista debe inspirarse para superar la naturaleza. El otro gran teórico, Leonardo, afirma lo mismo: "El ojo del artista en esto supera a la naturaleza, que las sencillas cosas naturales son finitas mientras que las obras que el ojo manda a las manos son infinitas, como demuestra el pintor en las ficciones de infinitas formas de animales y hierbas, plantas y lugares."

El problema de la imitación tomada de los clásicos, de Aristóteles principalmente, se vuelve fundamental a lo largo de todo el Renacimiento, objeto de un estudio siempre más profundo que da lugar a ásperas disputas de las que aqué se citarán las que sintetizan las dos tendencias fundamentales: una contraria a la imitación servil, que contrasta con la exigencia de renovación de los humanistas; otra obediente, apegada a los antiguos modelos. De la primera es iniciador el prehumanista Petrarca. En una de sus cartas (la xxxiI, 19, de las Familiares) el poeta toscano había comparado la relación entre los antiguos y los modemos con el parecido entre padre e hijo, diversos en todo y, sin embargo, semejantes por cierto aire y cierto tono: un parecido inefable e indefinible. Y en otra carta, Petrarca cita a Séneca que había utilizado otra afortunada analogía: la imitatio es semejante a la labor de la abeja que se alimenta de todos los zumos y, sin embargo, produce ella misma su miel. El encuentro con los poetas antiguos tenía, pues, que llevar a una verdadera creación. Para los humanistas originales la imitación no es entonces copia, y la familiaridad con los clásicos es el respeto a la tradición, provechosa sólo cuando sirve para despertar en los poetas su propia fuerza y los 
ayuda - -socráticamente, como dice Vasoli- a impulsar su inspiración nueva y diversa, a expresarse a sí mismos; si no, la imitación es cosa de simios y loros.

En las últimas décadas del Quattrocento surge, alrededor del mismo tema de la imitación, una disputa entre Agnolo Poliziano y Paolo Cortese en la que participan de manera violenta otros humanistas. Poliziano, como el gran poeta que es, desaprueba ásperamente a los imitadores de Cicerón así como a los eclécticos que mendigan el estilo como se mendiga el pan. A Paolo Cortese, quien le critica porque no se expresa como Cicerón, objeta: "Tú me dices que después de haber tanto estudiado a Cicerón; no me expreso como él. Pero yo no soy Cicerón y justamente de él he aprendido a ser yo mismo". Poliziano no desconoce la necesidad del estudio de los clásicos y el contacto con la tradición clásica, ni su función formadora, pero ésta debe llevar a la libertad del poeta que se expresa en otra civilización y con una lengua diversa. Finalmente, Cortese, al reafirmar la necesidad de la imitación, recurre a la imagen de Petrarca y reconoce que la imitación es el aprendizaje para lograr la originalidad. Al final de cuentas, el contraste, después de largas polémicas, concluye en el reconocimiento de que la formación sobre los clásicos y su ejemplo no deben excluir la libertad del poeta de ser él mismo. Como veremos, a esta disputa seguirá, en la primera década del siglo xvı, otra entre Pietro Bembo y Giovan Francesco Pico, cuando todavía no reaparece, triunfante, la Poética de Aristóteles, con el ambiente impregnado del neoplatonismo de Marsilio Ficino, lo cual cambiar los términos de la disputa.

\section{La fuentes del neoplatonismo}

El filosofo Platón, "quien ha fundado el sentido metafísico y el valor de lo Bello $^{3}$ de manera valedera para todos los tiempos, y cuya doctrina de las Ideas ha ido adquiriendo importancia siem-

${ }^{3}$ En el pensamiento antiguo, el arte y lo bello no coinciden y son considerados independientes uno de otro. 
pre mayor también para las artes figurativas", 4 penetra, junto con el neoplatónico Plotino, en el ambiente florentino de la segunda mitad del siglo xv, y precisamente con Marsilio Ficino, traductor de las obras de Platón, de Plotino y de los herméticos, entre otros. A partir de ellos, Ficino elabora aquella concepción de la Idea que tendrá una influencia definitiva en el pensamiento estético posterior del Renacimiento. Se trata, obviamente, de un Platón desvirtuado con respecto a sus ideas sobre el arte. Platón (República, Sofista), había condenado el arte en cuanto mimesis, inútil y pasiva duplicación del mundo sensible, nociva además porque es susceptible de excitar la parte pasional del alma que tiene que estar siempre sometida a la parte racional. Como se sabe, 10 bello es para Platón la manifestación de la Idea en el mundo empírico, y las ideas, antes de estar presentes en nuestro intelecto, subsistirían en un mundo hiperuranio ${ }^{5}$ como paradigmas de la realidad sensible que, en una primera fase del pensamiento platónico, era considerada distinta y separada del mundo trascendente de las ideas; sólo en la última fase de su pensamiento (Filebo y sobre todo Timeo), la realidad aparece modelada, por obra de un Demiurgo, sobre los prototipos ideales; pero el arte que en este caso venía siendo imitación de la imitación sensible, es decir, todavía más alejado del mundo de las ideas, sigue estando fuera de su sistema, a pesar de que su juicio sea al respecto menos negativo (y por eso Panofsky dice que la filosofía de Platón no es antiestética sino anestética). Sin embargo, de la metafísica de las ideas de Platón, deriva a lo largo de los siglos siguientes una serie de interpretaciones que, adaptando y modificando el pensamiento genuino platónico, tuvieron una importancia enorme en el desarrollo de la estética, término éste que empezo a ser usado sólo en el siglo xvin con Baumgarten; en el mundo antiguo se hablo siempre de poética.

Aristóteles, el otro gran filosofo que el pensamiento renacentista retoma en las últimas décadas de la primera mitad del siglo

${ }^{4}$ Erwin Panofsky, Idea, Florencia, La Nuova Italia 1952.

5 El mundo hiperuranio, sede de las Ideas platónicas, es el espacio situado más allá de las esferas del cielo. 
'XVI, busca superar el dualismo de su gran maestro y concibe las ideas como formas del mundo de la materia, es decir, como compenetración entre forma y materia, ofreciendo como ejemplo la unidad cuerpo-alma, y rehabilitando así el concepto de imitación que está en la base de su pensamiento estético. Esta concepción, extendida al campo de la estética, se prestaría a considerar como forma el interior 'fantasma' del artista y del poeta, que se encarnaría materialmente en la creación poética y figurativa. En el sistema aristotélico el arte, aun perteneciendo a la esfera de la actividad práctica, tiene un valor cognoscitivo, ya que la imitación que es objeto del arte es para él una manifestación innata del impulso humano al conocimiento y al saber. $Y$ por esto Aristóteles llega a considerar la imitación poética como más filosófica que la imitación de la historia. Por otro lado, si para Platón lo bello es la manifestación sensible de las ideas, para Aristoteles consiste en el orden, en la simetría, en el equilibrio, en una magnitud que se preste a ser facilmente abarcada en conjunto por la vista . Los dos conceptos de belleza pueden, como se ve, integrarse, lo que en cierta medida ocurrio en el Cinquecento. (Hay que recordar las tentativas de Pico, a finales del Quattrocento, de conciliar el pensamiento de los dos filósofos griegos).

Cicerón, otra importante presencia en el Renacimiento - al punto de desatar un ciceronianismo deletéreo y fanático atacado por Erasmo, y no solo por él sino por muchos italianos- es el primero que interpreta la Idea platónica y la forma aristotélica con una originalidad que ha sido reivindicada por Edmondo Cione y E. Panofsky. Cicerón contamina la originaria concepción platónica con elementos aristotélicos: interpreta la idea platónica no como objetivo paradigma ideal sobre el cual se modela el mundo terreno, ni como forma animadora y organizadora de la materia según Aristóteles, sino como "forma pensada" (la expresión es de Edmondo Cione quien utiliza un término de Gentile), es decir, pensada al interior del hombre - in interiore homineque daría lugar a la expresión artística. Por otro lado, Séneca, quien influye tanto en los mediocres dramaturgos italianos como 
en los grandes isabelinos, da a esa Idea in interiore homine una función psicológica independiente de toda correspondencia con la realidad. La idea metaempírica puede presentarse sólo a nuestro espíritu, de modo que el objeto de la representación artística no puede ser reconocido con los ojos en toda su perfección, sino que vive como puro fantasma en el alma del artista (Cione). Merece la pena citar un pasaje del Orator ciceroniano que confirma la valoración de Cione y de Panofsky: "En mi opinión, nada hay tan bello, en ningún género, como su original: pero no podemos percibir este original ni con el oído [Cicerón está hablando de la oratoria a la que considera arte] ni con ningún otro sentido, sino sólo mediante el espíritu. Por eso podemos imaginar algo que supere en belleza las mismas esculturas de Fidias, en su género las más perfectas, y también las pinturas ya mencionadas, ${ }^{6}$ porque cuando el artista creaba a Zeus o a Atenea, no contemplaba nin-

${ }^{6}$ Se refiere a la Mente Angélica, la más próxima a Dios. Quizá sirva sintetizar, aun brevemente, la cosmología religiosa ficiniana, como Marsilio la estructura en su De amore. Del Caos inicial $\rightarrow$ mundo sin formas como lo liama Platón- se forman por medio del Amor tres mundos: la Mente Angélica; el Alma del Mundo; el Cuerpo del Universo. La Mente Angélica se vuelve a Dios así como el ojo se vuelve al Sol, y ve los colores y las figuras del mundo. Nacida de Dios, se dirige por cierto apetito innato hacia Dios, su principio e, iluminada por su rayo, se enciende de amor. Al acercarse a Dios que todo puede, éste esculpe en ella la naturaleza de todas las cosas creadas. En la Mente Angélica se graban entonces todas las cosas que están en este Mundo: Ias esferas de los Cielos, de las Estrellas, la naturaleza de los vapores, las formas de las piedras, de los metales y de los animales y, dice Ficino, "esta especie de todas las cosas que son concebidas por la Mente Angélica con la ayuda divina, son las Ideas". EI Alma del Universo, generada por el Alma Angélica, se dirige a su vez hacia ella y hacia Dios. Presa del Amor, el Alma del Mundo recibe del Alma Angélica el ornamento de todas las cosas y se vuelve cuerpo del Universo. El Amor que preside a estos tres Mundos es el que despierta todas las cosas que duermen, ilumina las tenebrosas, da vida a las cosas inanimadas, forma las cosas sin forma y da perfección a las cosas imperfectas. Existe entonces una atracción entre Dios y el Mundo, ya que "todas las partes del Mundo, que son obra del mismo Artífice y miembros de una misma Máquina [...] están ligadas entre sí; de manera que puede justamente decirse que el Amor es nudo perpetuo y vínculo del Mundo, inmóvil sostến de sus partes, y firme fundamento de la Máquina Universal". En fin, según Ficino, todas las partes del cosmos se acercan una a otra por fuerza del Amor recíproco, como semejantes. Platón había dicho que el Cielo se mueve por amor innato. 
gún hombre real que pudiese reproducir, sino que su espíritu albergaba una excelsa forma de belleza: a ésta él contemplaba, dirigiendo su mano y arte según ese modelo. Puesto que en las artes figurativas hay algo de cumplido y excelente a cuya forma ideal se refieren, y en la imitación artística están aquellas cosas que no caen bajo el control de los sentidos (o sea, los entes divinos que hay que representar), de esta misma manera percibimos la forma de la perfecta elocuencia con el espíritu, y con los oídos captamos sólo su copia. Platón, ese sumo escritor y maestro no sólo del pensar sino también del decir, llamaba 'ideas' a esas formas. Él niega su temporalidad y afirma su carácter eterno, porque las considera fundadas en la razón y en el pensamiento. Lo remanente nace y muere, se transforma y pasa, sin nunca quedar en un solo y mismo estado".

Plotino, otra de las grandes fuentes del neoplatonismo florentino, cuya metafísica de la luz influirá en la cosmología religiosa de Marsilio Ficino, da al arte la dignidad metafísica que Platón le había negado. El arte es la manifestación de la Idea en la materia. Se da lo Bello, dice Plotino, cuando la forma triunfa sobre la materia. El artista, realizando la forma en la materia, viene a encontrarse en la posición misma del Intelecto Supremo que da el sello de la forma a la materia. Sin embargo, Plotino no considera la materia aristotélicamente, como cera dócil al recibir huellas - la materia aristotélica anhela a la forma como su integracion- sino como principio negativo y resistente a la virtud plasmadora. Y de su premisa metafísica - el mundo como mal-- deriva implicitamente que el arte como realización de la idea en el mundo sensible es degradación: la forma, al realizarse en una materia degradada, se degrada ella también. Panofsky subraya las contradicciones de Plotino y observa que el parangón plotiniano del artista con el Intelecto Supremo se resuelve en un valor negativo. Si es cierto que el Intelecto Supremo es originariamente perfecto y en el realizarse en el mundo de la materia, que Plotino concibe como mal, se degrada y no se enriquece, el artista que realiza'su obra en el mundo sensible cumple, sí, una obra análoga a la divi- 
na, pero inútil y disipadora. La concepción plotiniana, puntualiza al respecto Cione, podía ser superada s6lo invirtiendo el punto de vista de Plotino y considerando un enriquecimiento lo que para él era una degradación. Para eso, observa justamente Cione, se tenía que llegar al concepto de productividad del espíritu y tal concepto que es tipicamente moderno, fue intuido por primera vez en el campo teológico, "gracias a la idea cristiana de la creación divina que rompe con el presupuesto estético y realista de la metafísica griega e inaugura la era de las concepciones dinámicas y espiritualistas". Y según Cione, este concepto de la productividad del espíritu fue elaborado, fuera de la estética, por la patrística y la escolástica. Con respecto al arte, el pensamiento medieval lo interpreta, análogamente a la producción divina, como "una producción que brota de la Idea interior y es proyectada al exterior"; pero, observa.Cione, se trata de una intuición que no es desarrollada a fondo. Sin embargo, el originario optimismo cosmico que es una aportación de la filosofía cristiana y medieval y que hereda el naturalismo renacentista, supera la concepcion pagana de Platón según la cual el mundo sensible es condenable, de Aristóteles para quien la materia es potencia pasiva, y de Plotino que identifica el mundo de la materia con el mal. Partiendo del optimismo cósmico cristiano, el naturalismo renacentista rehabilita la naturaleza y con esta visión naturalista están relacionadas las teorías de la imitación y de la idealización artística de la naturaleza, que se inician precisamente con Alberti.

Las ideas o tendencias en las que se ha rápida y esquemáticamente incursionado, constituyen la fuente, el material ecléctico que los humanistas y teóricos renacentistas elaborarán.

En las últimas décadas del siglo xv, la influencia del neoplatonismo de Ficino y de Pico y su difusión en los medios literarios y artísticos, enriquecen la concepción humanista y las discusiones sobre el fenómeno artístico en sentido especulativo y metafísico, no obstante que Ficino no se haya ocupado especificamente del arte. Bajo esa influencia los tratados del último Quattrocento acentúan el valor suprasensisble y metafísico de la poesía y del 
arte. Comienza la doctrina de la Idea que influyo en los orígenes de la estética modema. Partiendo del principio plotiniano de la luz finita del mundo, emanación del infinito esplendor de la luz divina, Ficino (De Amore) sostiene que el mundo es la mezcla de la sombra y de la lux summa luminum, en la que la luminosidad divina se confunde con la tiniebla de la materia. Es decir, la luz divina que desborda del Ser, se expande por el universo de grado en grado: Mente Angélica, más próxima al Alma del Universo; Naturaleza; los cuales, incitados por el Amor, tienden a regresar en un movimiento circular a su punto de origen, para unirse con el Sommo Bene del que emanan. A nivel de la concreta creación artística, un ejemplo de adecuación de los artistas a las ideas neoplatónicas sobre la luz, lo ofrece Miguel Angel en la capilla de los Médicis en Florencia: la luz desciende de la cúpula central de la capilla y se propaga gradualmente hasta sus partes laterales situadas en la penumbra, donde están la estatuas de los Médicis.

Marsilio insiste sobre la función mediadora de la belleza que es la manifestación corporea de la verdad inteligible y de la unidad divinas, a las que el amor que es aspiración, anhclo, fruición de esa belleza, tiende. La belleza representa, dice Ficino, el esplendor del Sommo Bene en el orden sensible, y el alma, impulsada por el amor, que es anhelo de Dios, remonta de belleza en belleza a la primera de todas las formas, a lo Absoluto, primero y puro Bello, en el que se refleja la misma esencia de Dios. Dice Ficino: "el esplendor de este rostro (de Dios) que se refleja o en el Ángel o en el Ánimo o en la materia del mundo, se debe llamar belleza universal; y la apetencia que a ella se dirige es universal amor [...] un solo lumen de sol, de los colores y figuras de todos los cuerpos, que se refleja en los ojos; los ojos que con la ayuda de cierto rayo suyo, reciben el lumen del sol. Porque todo este lumen [...] todo este orden del mundo que se ve, se toma a través de los ojos; no en el modo como se encuentra en la materia de los cuerpos, sino en el modo en que se halla en la luz que se mete en los ojos". Todo es luz y belleza que se manifiesta en la perfecta arquitectura de los diversos grados del Ser. La belleza 
es entonces el símbolo de la perfección que cada ser trae de su esencia ideal, y contemplar la Belleza con amor es el solo fin al que debe aspirar el Alma para saciar su natural tendencia hacia Dios. La mente humana es capaz de contemplar en la belleza de las imágenes sensibles su forma inteligible y de reconocer, más allá de las aparencias, el esplendor de las esencias eternas, puras; y estas son las ideas que revelan la belleza interior de todas las cosas, las verdaderas realidades metafísicas de las que los objetos sensibles dan sólo imágenes y lejanos reflejos. Las Ideas, inmanentes en el espíritu divino, son los ejemplos sobre los cuales está construida toda la realidad, y el alma humana puede entenderlas porque sus impresiones están ya innatas en ella desde su existencia extraterrena, y constituyen el vínculo entre el alma y la mente de Dios. El olvido y la ciega experiencia de los sentidos han casi apagado estas scintille della luce originaria, que quedan confusas y que pueden otra vez encenderse, porque la idea de 10 bello está impresa en nuestra mente $a b$ aeterno y hace renacer aquel deseo apasionado que eleva al hombre sobre el hombre y lo convierte en Dios. Por eso, cada creación estética es un acto de meditación y elevación interior, de éxtasis. Inspirado por Dios, el artista tiene la capacidad de traducir un contenido puramente inteligible en una forma sensible, y por eso el arte tiene un valor metafísico absoluto. La congruencia entre idea inteligible y representación sensible hace, pues, de la obra de arte el signo, la cifra de otra realidad.

Así rechaza Ficino la condena platónica del arte como "mimesis de una mimesis" y excluye el significado realista del arte cuya tarea no es reproducir el aspecto sensible de las cosas sino la visión simbólica de la verdad ideal. Esta concepción transforma el problema de la imitatio, puesta por la cultura humanista en relación con los modelos de la antigüedad. La imitatio neoplatonica es la imitación de una Idea que puede encarnarse en la poesía o en la prosa o en la música o en las artes —arquitectura o pintura o escultura- y da al artista una dignidad más alta, de intérprete de los misterios divinos. Sin embargo, no resurge inte- 
gralmente, como observa Vasoli, la mística de Plotino (que hemos visto criticada por Panofsky) que atribuye a la actividad estética la función suprema de conocimiento de lo Absoluto, sino que renueva la doctrina del arte como revelación.

Así la Idea que la patrística (con Agustín) y la escolástica (con Tomás y Bonaventura) habían puesto in mente Dei, se vuelve potencia del intelecto humano. Raffaello, en una célebre carta de 1516 a Baldassare Castiglione, escribe que para pintar a una mujer bella, él necesitaría ver a muchas mujeres bellas y como hay penuria de ellas, se sirve de cierta idea que le viene a la mente. Él no produce sus obras según modelos externos, sino serviéndose, como dice textualmente, "de cierta idea que me viene a la mente. Si ésta tiene en sí alguna excelencia de. arte, yo no sé; bien me esfuerzo en lograrla". Y Panofsky comenta que "esas extraordinarias palabras demuestran que Raffaello había reconocido poder deducir de su 'íntima representación', la imagen de la perfecta feminidad, independientemente del simple objeto externo sin, por lo demás, atribuirle un origen metafísico ni un valor normativo". Se limita, dice Panofsky, a una constatacion, sin pensar en la relación entre Idea y Experiencia. Lo mismo ocurre con Durero, subraya Panofsky, quien habla de "un íntimo, secreto tesoro del corazón" que se forma sólo cuando el artista, después de muchas elaboraciones, ha tomado plena posesión de sí, y de tal plenitud puede forjar en su interior una "nueva criatura" en la figura de una cosa; también Durero, dice Panofsky, hubiera dicho como Raffaello: "no sê". El mismo Alberti, cuya idea de belleza está ligada con la experiencia, no llega a precisar que tenga origen en la experiencia. Y tampoco Vasari, quien va más allá de la mera constatación, llega a dar un fundamento filosófico o a deducir consecuencias teoricas.

El concepto de la armonía y de la perfecta disposición formal de la obra de arte, madurado en el ámbito humanista desde el inicio del siglo xv, se vuelve símbolo de la perfecta armonía universal, de la belleza ideal: manifestación del Ser. Gracia y belleza estética, armonía, euritmia se enriquecen con una profunda aspi- 
ración metafísica. La influencia platónica continúa en las doctrinas estéticas del Cinquecento y se manifesta en el valor 'ideal' que se atribuye a la imagen artística. Un estudioso observa que la adhesión al valor alegórico y analógico del arte está presente sobre todo en los escritores y poetas que viven profundamente el drama religioso de su tiempo, como en Miguel Angel Buonarroti $y$, como se verá al final del siglo xvI, en Francesco Patrizi y en Giordano Bruno, quienes reivindican el valor metafísico del arte y proclaman la libertad del artista respecto de toda regla y vínculo externo.

La belleza universal se manifiesta en la visibilidad de las ideas que, difundida por Dios en esos varios grados, refleja la misma esencia divina y revela a la mente humana el orden y la perfección del universo. El neoplatonismo, con su idealización de la belleza como manifestación de la bondad divina, inspira la tratadística sobre el amor y la belleza y ofrece una base metafísica a la teoría de la imitación y de la Idea.

Cuando explota la segunda polémica entre Pietro Bembo y Giovan Francesco Pico acerca de la imitatio —en 1512 y 1513 . el ambiente, impregnado de neoplatonismo, ha mudado y la disputa tendrá facetas que faltaban en la primera entre Poliziano y Cortese. Giovan Francesco Pico, igual y más que Poliziano, sostiene que los grandes poetas se han siempre independizado de la imitación, preocupados sólo de expresar su propia personalidad. Admite el canon imitativo sólo si la vocación poética es innata en el escritor, además, el poeta o el artista no debe servirse de un único paradigma, limitado y parcial, sino del ejemplo de muchos autores, es decir, de la tradicion. Bembo, en su epístola de respuesta, cuestiona el ideal ecléctico de Giovan Francesco Pico y postula la necesidad de referirse a un único ejemplo, el modelo clásico perfecto $\rightarrow$ sin excluir ejemplos más recientes de la literatura trecentista, como Petrarca y Boccaccio- que sinteticen la perfección literaria y artística de su época. Sin embargo, bajo la influencia neoplatónica, los dos comparten la convicción metafísica de la existencia de un modelo ideal de escritura. En la línea 
de Ficino continuarán los tratadistas del Cinquecento insistiendo en la implicación entre lo Bello ideal y lo Bello visible: Diacceto, Vasari, y otros, que durante sus encuentros en los Orti Oricellari de Florencia continúan la tradición platónica y neoplatónica. Con Zorzi o Luca Pacioli la visión neoplatónica se convierte en la simbólica descripción del universo concebido como una obra maestra arquitectónica y musical, gobernada por las puras leyes de la armonía, imagen de Dios expresada en un concierto de proporciones admirables. Se insiste en la esencia del todo espiritual de la belleza considerada como la misma imagen de Dios que se difunde y manifiesta en todas las cosas. Baldassare Castiglione, en el Cortesano (1528), dirá que "la belleza es un flujo de la bondad divina". León Hebreo; en sus Diálogos de Amor (1536), exalta el amor universal que anima y une todas las cosas. Por otro lado, la difusión del neoplatonismo alimenta la doctrina del entusiasmo poético, de la inspiración que hace al poeta semejante a Dios, del elemento fantástico de la poesía como acto de "furor poćtico", el daimon del que habla Platón, el lado demoníaco y amoroso que abre el camino hacia el concepto moderno de 'genio' y hacia la autonomía de la poesía.

El neoplatonismo coexiste con las instancias humanistas de una perfecta humanitas, de un sereno equilibrio espiritual; de una "concordia del hombre consigo mismo y con la realidad" (Vasoli); con la exigencia ética humanista de la participación del 'sabio' en la realidad humana; de la concordia entre pensamiento y acción - "vida contemplativa" y "vida activa" - que tenían que constituir la finalidad de la cultura para crear un mundo humano ejemplar.

El gusto clasicista, asi alimentado por las doctrinas platónicas, se encuentra de nuevo con la Poética de Aristóteles que regresa al primer plano al final de la primera mitad del siglo xvi, en el original griego. Traducida por primera vez al latín por Lorenzo Valla (1498), y luego por Daniello (1536), la Poética penetra definitivamente en la cultura del Cinquecento. Empiezan las ediciones críticas en lengua vulgar, y continúan las discusiones y las polémicas sobre el tema de la imitatio, debatido ahora a la luz del texto aris- 
totélico. El arte viene siendo considerado, no menos que la filosofía, una forma de conocimiento y de "adiestramiento en la vida civil, para introducir virtud en los hombres [...] en beneficio de una bien ordenada república". Los aristotélicos subrayan el carácter cognoscitivo y la característica racional de la poesía, y por eso se ven obligados a individuar su naturaleza, la especificidad de su función estética, en relación con otras formas de conocimiento como la historia. Además, a lado de la imitatio, aparecen otros conceptos fundamentales, como lo 'verdadero' y lo 'verosímil' en el arte, alrededor de los cuales se encamizan los teóricos. Fracastoro y Castelvetro se detienen sobre todo en la distinción entre la poesía y la historia, tratada por Aristóteles, quien había subrayado la superioridad de la primera sobre la segunda: mientras que el historiador reproduce acontecimientos e individuos tales como fueron en la realidad y en orden cronológico, el poeta los representa en su esencia universal y en sus caracteres absolutos e ideales. La idea de la mayor universalidad de la poesía con respecto a la historia termina por no hallar impugnadores.

Sin embargo, objeto de interpretaciones diversas es la afirmación de Aristóteles respecto a los límites y a la extensión poética: "Si alguien pone en versos materia extraída de la medicina y de la filosofía se le da de costumbre el nombre de poeta; pero, fuera del verso, no hay nada en común entre Homero y Empédocles". Varias fueron las interpretaciones de este pasaje, según la diferente mentalidad y las tendencias de los aristotélicos. Algunos teóricos (Varchi) en la línea aristotélica, incluyen en la matèria poética las pasiones, las costumbres, los actos humanos; otros (Capriano) extienden los límites de la poesía a cualquier 'facultad' del hombre. Lionardi (Dialoghi della invenzione poetica, 1554) exige que el poeta sea historiador y filosofo. Bemardo Tasso va más allá: "Es necesario que el poeta tenga conocimiento del arte y de las ciencias..., que sea geógrafo. astrólogo y teólogo, y de toda otra ciencia sea buen entendedor". Scaligero hace una distinción entre poetae philosophi (Empédocles, Lucrecio), poetae morales (Solón, Tirteo) y poetae puri, los que imitan so- 
lamente la vida y los acontecimientos humanos. El poeta puede entonces abarcar toda la esfera de las pasiones y de las actividades humanas. Fracastoro declara que no existe una materia peculiar del poeta. Eliminado todo criterio de argumento o de contenido, la 'esencia del arte' radica en el logro de lo universal y en la intrínseca coherencia racional del arte.

\section{Los géneros literarios}

En la última mitad del Cinquecento se empieza a buscar la sistematización de las normas retóricas y poéticas derivadas de la tradición clásica y humanista y de los géneros literarios: lírica, poema heroico, poema narrativo (novelesco), comedia, tragedia $y$ drama pastoril. La tragedia es el género más discutido. La elaboración de las normas y las reglas sobre la tragedia, deducidas supuestamente de la Poética de Aristóteles, cristaliza en las tres férreas reglas de unidad de tiempo, lugar y acción que en la Poética no presentaban carácter de imposición, ya que eran más bien derivadas a posteriori de los textos mismos de la tragedia griega. Sin embargo, los teoricos del Cinquecento codifican de la manera más severa las reglas 'aristotélicas', a las que los dramaturgos italianos, con muy pocas excepciones mediocres, obedecieron ciegamente, mientras que fuera de Italia fueron utilizadas con libertad. Un ejemplo: Lope de Vega quien en su Arte nuevo de hacer comedias declara:
nunca reparo tanto en los preceptos antes me cansa su rigor, y he visto que los que miran en guardar el arte, nunca del natural alcanzan parte.

Alrededor de la catarsis, ${ }^{7}$ como la finalidad de la comedia y de la tragedia para purificar los ánimos de las pasiones e inducir a los

'Interesa hacer notar que la palabra 'catarsis' es un término de origen médico que significa 'purga'. Y en el sentido de purga o purificación la uti- 
hombres a costumbres buenas y severas, y sobre sus características y funciones, se encarnizaron las discusiones sobre todo de los aristotélicos contrarreformistas que en el clima de la Contrarreforma encontraban en la catarsis un sostén para la nueva política cultural de la iglesia católica. Con la Contrarreforma, triunfa de hecho la exigencia pedagógica.y moralista del texto aristotélico, del docere et delectare, es decir de un fin pedagogico y moral extrínseco al arte, seguido sobre todo por Giraldi Cinthio, Scaligero, etc.

La clasificación de los géneros literarios que surge de la Poética aristotélica es uno de los problemas más candentes y debatidos del Cinquecento. Como se sabe, la Poética comienza dividiendo la poesía en dramática y narrativa. Esa bipartición, con neta preferencia del filosofo griego hacia la primera - sobre todo la tragedia - no podía sin embargo abarcar toda la producción poética renacentista, y los teorizadores tuvieron que sustituirla con la tripartición en dramática, épica, lírica (esta última podría corresponder quizá al ditirambo al que alude el filosofo y que, sin embargo, queda fuera de su clasificación), ya que no se podía negar cáracter de poeta al latino Horacio o al italiano Petrarca. De todas maneras, quedaban muchas preguntas: ¿cómo situar en el ámbito aristotélico la nueva producción renacentista? ¿QQue eran los poemas de Dante, de Ariosto, etc.? El poema de Ariosto ¿era épico o narrativo? Eran preguntas que no encontraban fácil respuesta. La influencia de la Poética era tan grande que Guarino Guarini, para poder permanecer en su ámbito, denomina su propia novela pastoril, $l l$ pastor fido, tragicomedia. O para dar otro ejemplo, el caso más trágico del angustiado Tasso que se preocupa de obedecer a las reglas aristotélicas, aun permaneciendo en la línea neoplatónica. No se llegaba todavía a entender la relación entre cada particular obra literaria y el género que nunca se adecuaba a la obra individual sino aproximadamente, y que además

liza Aristóteles. Ya Platón había definido la catarsis como la "elección que conserva lo mejor y expurga lo peor". (Ver Diccionario de filosofía de Nicola Abbagnano). 
puede sólo orientar pero no determinar el juicio estético. En el Renacimiento, de la separación de los géneros se derivan las reglas normativas a las cuales Castelvetro y Scaligero pretendían que se conformaran los poetas, si querían crear obras dignas. Ante la tiranía de los géneros se rebelaron, entre otros, Francesco Patrizi y Giordano Bruno. Sin embargo, es impugnada la tendencia normativa pero no la necesidad de la clasificación.

Por supuesto, el drama pastoril, el poema heroico y el poema novelesco, géneros nuevos, fueron los más rebeldes a la teoría aristotélica. Trissino acerca la épica a la tragedia para, de ésta, derivar reglas y quizá legitimación del nuevo género, indicando. la afinidad entre la imitación de las gestas y la de las costumbres de los hombres ilustres. Sin embargo, su tentativa no hizo más que revelar el contraste entre las normas aristotélicas y los grandes poemas (el Orlando furioso de Ariosto y la Gerusalemme liberata de Torquato Tasso).

Giraldi Cinthio, consciente de la novedad de las formas épico novelescas, la creación poética más grande del Renacimiento italiano, afirma que el nuevo género es una forma desconocida por los griegos y, por tanto, la imposibilidad de adecuarlo a los esquemas de la Poética. Pero la polémica más violenta surgío acerca de la Gerusalemme, que Tasso había escrito inspirándose en la historia, y que respondía a todas las exigencias morales, religiosas y filosóficas del nuevo espíritu de la Contrarreforma. Tasso conocía las doctrinas estéticas de Platón y la tratadística neoplatónica sobre el amor y, como otros, concebía el arte como ideal transfiguración de la realidad, y la belleza como semblante o imagen del Bien que no puede ser descrito o limitado por el tiempo, por el lugar, por la materia o por la palabra. Fiel a los cánones aristotélicos, su épica está, sin embargo, impregnada de inspiración platónica y de un entusiasmo que manifiesta una conciencia artística original y extraña a la mayoría de los aristotéli$\cos$. La controversia sobre la Gerusalemme Liberata atestigua cuán ásperas han sido las querellas que el culto neoplatónico y el aristotélico suscitan entre las dos doctrinas; que fueron, además, 
intensas entre los representantes de la misma doctrina aristotélica, en cuyo interior coexisten tendenciaś diversas y antagónicas. (Por otro lado, hubo también una tendencia a conciliar ambas doctrinas, en la línea humanista del siglo xv).

Torquato Tasso termina la Gerusalemme Liberata en 1575, y la somete a los revisores —entre ellos Sperone Speroni- quienes la destruyen. Lleno de escrúpulos religiosos y literarios, subyugado por la disciplina aristotélica y por el Concilio de Trento, se vuelve "inquisidor de sí mismo", como dice Francesco De Sanctis, y se acusa de herejía ante el tribunal de ' la inquisicion. Angustiado, da signos de violencia y de locura, y es encarcelado en el castillo de Ferrara, luego internado en un hospital donde permanece de 1579 a 1586 . En 1591 rehace la Geruralemme y publica la Gerusalemme Conquistata. Afortunadamente el texto original no se perdió y fue publicado en Ferrara en 1581, suscitando las iras y las críticas feroces de la Accademia della Crusca - De Sanctis la llama "el Concilio de Trento de nuestra lengua"- que excomulgaba a cuantos escritores no se sometieran a sus dogmas.

La polémica entre Tasso y sus detractores revela todos los límites y las contradicciones de la codificación de las reglas, y abre la vía a un nuevo modo de concebir la posición aristotélica. Se inician los ataques sistemáticos a las doctrinas de Aristóteles. Sobre todo los de Francesco Patrizi, quien ya en 1562 había negado todo valor doctrinal y filosófico a la retórica clásica, juzgándola cosa de cortesanos. En La Deca disputata de 1586, inspirándose en el platonismo, Patrizi ataca a Scaligero y sostiene la idea de que el estudio del arte no puede depender de cánones poéticos, de una regla fija de expresión y de método, ni de una doctrina establecida como autoridad indiscutible; sino del analisis directo de la obra de arte, y de la adecuación de la teoría a la efectiva naturaleza de la obra. Por otro lado, el estudio de los orígenes y de las primeras formas poéticas lo lleva a señalä el 'entusiasmo' como la verdadera fuente de la poesía, a negar que la obediencia a las reglas pueda sustituir la vocación artística y, asimismo a hablar de ' genio' poético en contraposición con el rigu- 
roso racionalismo de los aristotélicos. En su ataque, Patrizi retoma los motivos de la cultura humanista y de los tratados platóni$\cos$, y termina aclarando los aspectos más contradictorios de la imitación al afirmar que las ideas aristotélicas, si fueran bien estudiadas, tendrían como consecuencia que "todas las hablas, todas las escrituras filosóficas y cualquier otra cosa serían poesía, ya que están hechas de palabras que imitaciónes son". La poesía debería entonccs abarcar cada forma y aspecto del mundo humano. En su polémica contra el Tasso (Trimerone), Patrizi afirma que "las enseñanzas poéticas de Aristóteles no eran ni propias, ni verdaderas, ni suficientes para constituir arte scienziale de poética ni para formar poema alguno, ni para juzgarlo" (Vasoli); e insiste platónicamente en el misterio, en la naturaleza 'oculta' de la poesía, señalándola como una particular y singular representación hasta entonces no aclarada ni "por otros demostrada". Sólo la práctica puede hacer las 'reglas', y sólo la 'divina inspiración' es fuente de perfección y de virtud poética. El sentimiento del arte y de la bclleza es entonces irreductible a los esquemas tradicionales. Queda por tanto muy clara la afirmación de Patrizi de una libertad poética.

Patrizi lleg6, como dice Vasoli, a las conclusiones más audaces alcanzadas por el pensamiento estético del Renacimiento. Pero su rebeldía en contra de los regolisti di poesia, como Giordano Bruno llama con menosprecio a los aristotélicos ortodoxos, no es un hecho aislado. Los tratados de inspiración platónica, como el Dialogo de furore poetico (1581) de Frachetti, van en la misma línea. En 1585 Giordano Bruno, inspirándose también en las fuentes platónicas, sostiene en sus Heroicos furores que "la poesía no nace de las reglas sino por ligerísimo azar; más que las reglas derivan de la poesía; y por eso son tantos los géneros y las especies de verdaderas reglas, cuantos son los genios y especies de los verdaderos poetas", reivindicando así de manera definitiva la libertad del genio poético y su creatividad, y defendiendo la libertad de la expresión poética. A Bruno seguirá Tomaso Campanella, gran poeta y filósofo, quien concluye las polémicas del 
Cinquecento. En su Poetica en lengua vulgar -que traducirá al latín- ve en la belleza el signo del bonum así como en lo feo el signo del malum, y considera el arte como la creación del genio poético. La poesía es la flos scientiarum. La últimas aportaciones de Patrizi, Bruno y Campanella, pensadores de transición, anticipan la problemática del barroco que rcflexionará en los conceptos de ingenio, agudeza, gusto, imaginación, genio y sentimiento.

El problema de los géneros dio lugar a controversias durante siglos, que sin embargo han ayudado a la comprensión del hecho creativo que está más allá de las reglas y de las divisiones de los géneros. ${ }^{8}$ Sólo recientemente y gracias a Benedetto Croce, se ha llegado a distinguir la universalidad de la poesía respecto de la particularidad de los géneros, así como a considerar el concepto de arte como uno e indivisible. Los géneros, útiles para la historia de la cultura, o instrumentos cómodos para los historiadores de la literatura deben, según Croce, ser negados en el campo de la estética y no pueden ser criterio de juicio estético. No obstante, como dice ironicamente Mario Praz, los géneros, echados por la puerta de la filosofía, regresan por la ventana de lo empírico.

Para concluir, la larga polémica sobre la Poética de Aristóteles fue muy provechosa en el sentido de que impulsó el largo debate sobre el arte, apasionado y a veces violento, y tuvo una función importante que permitió profundizar sobre el hecho artístico e influyó en las culturas occidentales. El concepto aristotélico del arte como pura actividad cognoscitiva, el concepto de la imitación ideal como universal intuición de la verdad; el principio de la racional coherencia de la obra de arte, tuvieron en el Seiscientos un desarrollo que de estos puntos partio. Entre los dos siglos Galileo Galilei, quien consideraba el arte como fruto de la fantasía y de la invención, reconoció la validez de esos conceptos. La influencia de las poéticas aristotélicas, a través de Scaligero y Castelvetro, fue grande en España, Inglaterra, Francia, sobre todo

${ }^{8}$ Voltaire dice que no es posible clasificar las obras humanas como hacemos con los metales, los minerales, los elementos cuya naturaleza es siempre la misma. 
en la tratadística del grand siècle, con Boileau: De la lección renacentista partieron Lope de Vega, Pinciano; Sidney, Milton etc., para elaborar su concepción poética, Las póéticas del Renacimiento son un punto de partida obligado del pensamiento estético, que en su desarrollo posterior tenía que llevar a la afirmación de la autonomía y heterogeneidad del arte, cuyo proceso es objeto del importante y exhaustivo estudio de Luciano Anceschi en su Libro Autonomia y Eteronomia del arte. 